\title{
The Evaluation of Analytical Models for Orthogonal Cutting Process
}

\author{
M.R. Vaziri Sereshk \\ Assistant Professor, Department of Mechanical Engineering \\ University of Tehran \\ Tehran, Iran
}

\author{
P. Heydarizadeh \\ Graduate student of Mechanical Engineering \\ University of Tehran \\ Tehran, Iran
}

\author{
S. M. Mostafavi \\ Senior Consultant Engineer \\ Iranian offshore oil company
}

\begin{abstract}
In Macro Mechanics view, Machining involves extremely localized and nonlinear physical phenomena that occur over a wide range of temperatures, pressures, and strains. The complexity of the system has hindered progress in predictive modeling of machining processes. Many different types of models ranging from theoretical to empirical have been developed, but the wide variety of the models makes performance assessment difficult. The goal of the present project is to assess the ability of available machining models to predict the outputs of machining processes. The approach involves calibration of the analytical models based upon data typically available on the shop floor and comparison of the outputs of the models and experiments. The experiments of the assessment of machining model (AMM) project that accomplished by (NIST) have been used. By comparing the cutting forces and chip thickness measured experimentally with the prediction of various theories it is appeared that empirical model existing in the standard charts presents the best prediction for the horizontal cutting force, however the result of hybrid models are acceptable too. The best prediction of vertical thrust force is obtained using Lee \& Schaffer, while regarding the chip thickness, the best result belongs to Merchant \& Ernst model.
\end{abstract}

Keywords-orthogonal cutting; analytical model; empirical model; cutting forces; chip thickness

\section{INTRODUCTION}

In 1998, Merchant estimated that $15 \%$ of the value of all mechanical components manufactured worldwide is derived from machining operations [1]. However, despite its obvious economic and technical importance, machining remains poorly understood. Machining research is driven by both ardent scientific curiosity and tremendous practical and financial utility. However, even though these two motivations are often at odds, neither can truly advance without the other.

The research literature on machining problems is vast (see for example Komanduri [8], Shaw [6]). Probably the earliest scientific report on the formation of a chip was presented in 1881 by A. Mallock [9] in the Proceedings of the Royal Society of London. Thus, before the beginning of the 20th century, notable empirical and theoretical studies of machining were already underway. The next period of development occurred in the 1930's and 1940's. The study of machining mechanics was for the first time placed on a solid physical and mathematical foundation by the work of Piispanen [10], Ernst [11], and Merchant [12-15]. Since then, four formal categories of cutting models have emerged: (1) analytic models; (2) slip-line models; (3) mechanistic models; and (4) finite element models. Each approach has certain advantages and shortcomings. The choice of a particular cutting model depends on the information desired, the required accuracy of this information, and the available resources. Availability of laboratory equipment enabling accurate process measurements is of paramount importance to the development of accurate models. The literature on experimental measurements in machining is extremely vast. However, comprehensive review articles and textbooks can be consulted for further information and references [6], [7], [8].

Development and complexity of machining models make them inexplicit to compare by their abilities and their defects. The goal of the study of Machining Models is to provide an assessment of the ability of current models to predict the practical behavior of machining processes. In this research the performance of well-known analytical models including Ernst and Merchant, Lee and Schaffer, Palmer and Oxley, and an empirical model presented in Ulrich standard handbook, [2] and a hybrid model (analytical as well as empirical) in prediction of machining forces and chip geometry have been assessed in comparison with AMM experimental data reported in reference [4].

\section{MECHANISTIC MODELING}

Mechanistic modeling is an analytical approach based on a semi-empirical method capable of accurate prediction of cutting forces in a wide range of complex machining operations [28-29], [5]. This approach is based on the assumption that cutting forces are proportional to the uncut chip area. The constant of proportionality, called the specific cutting energy, depends on the work piece material, the cutting conditions, and the cutting geometry [3]. The actual function is then determined by fitting experimental data in a process called calibration. Calibration can be based on simple orthogonal or oblique machining set-ups; geometric transformations can then be applied to predict cutting forces for a complex, three- dimensional machining process [29]. 
This simplifies the calibration set-up, but the need for testing is not eliminated. Mathematical equations and charts of material properties are noted in [3] and are used in this study as hybrid model.

Analytical model of [16-18] creates the relations between components (for example between the cut and thrust forces and the perpendicular and tangent forces) based on the geometry of the cutting. These models are very easy to use, but require prior knowledge of the shear angle, medium friction angle, and chip angles. These values must be determined experimentally, which restricts the use and accuracy of these models.

\section{ERNST AND MERCHANT MODEL}

The first complete analysis of the calculated angle of the cutting is done by Ernst and Merchant [16]. This analysis assumes that chip is a rigid body under the influence of the forces of shear surface and the contact surface of chip with the tool that had been balanced. This theory is based on the underlying assumption that the shear angel is considered to make the least work in cutting process. The problems of this approach is that in this model there is a velocity discontinuity thus work - hardening strain and strain rate, which are important in practice, cannot be considered.

$$
\varphi=45^{\circ}-0.5(\beta-\gamma)
$$

Where $\Phi$ is the shear angel, $\beta$ is average friction angle between chip and tool (that equals: arc tang $\mathrm{Ff} / \mathrm{Fn}$ ), and $\gamma$ is the rake angel. In this model the shear surface is the primary region of deformation.

\section{LEE AND SCHAFFER MODEL}

The slip line models [19-27] Depends only on material properties and not to the experimental data. These models predict the Mechanical response and temperature distribution and are consistent with stretching, the stretch rate and temperature-dependent models.

The Lee and Schaffer [18] theory is the result of elastic theory in solving plane machining problems with these assumptions:

(1) The rigid material is formable. It means that elastic strain during deformation is small and when the stress is greater than yield stress, yielding will continue with a constant stress. (There will be no work hardening during elastic deformation)

(2) The material behavior is independent of deformation
(3) Temperature rising during the deformation is neglected.

(4) The effect of inertia caused by material acceleration is neglected.

(5) In this theory assumed that the deformation is just appears in the plane forming from tool tip to the intersection of free surface of chip and work piece (means shear plane). The relation between the angels is as follows:

$$
\varphi=45^{\circ}-(\beta-\gamma)
$$

This equation is not valid in the case of $\beta=\pi / 4$ and $\gamma=0$ because the shear angle becomes zero. In the cases that the friction is large and the shear angle is small, the condition of appearing built up edge is present.

\section{PAlmer AND OXley Model}

In Palmer and Oxley model the effects of strain and strain rate hardening and temperature softening are included. The primary shear zone is considered as a volume. The proposed shear plane angle is as follows:

$$
\varphi=50^{\circ}-0.8(\beta-\gamma)
$$

In addition to mentioned analytical models, the empirical model presented in reference [2] is considered. This model is based on the standard charts come from several separated experiments on a wide range of materials.

\section{THE EXPERIMENTS OF THE AsSESSMENT OF Machining Model (AMM) ProJect}

Ivester et als. [4] carried out a set of experiments to be a data source for evaluation of the performance of machining models. The experiments were performed simultaneously in the four laboratories (NIST, Ford Motor Company, General Motors, and Caterpillar). The orthogonal cutting of steel (AISI) 1045 using a general purpose tungsten carbide /cobalt (WC/Co) insert was performed. The simplest grade of carbide was chosen to simplify tool-material modeling. Both uncoated and titanium nitride coated inserts are used. The merits of this process are: (1) the machining of AISI 1045 steel has significant relevance in the automotive and heavy equipment industries; (2) the material properties of AISI 1045 steel and general grade carbide are well known; and (3) the work piece and tool materials are easily obtainable in the configurations necessary for the tests. The used cutting conditions and tool geometry are presented in Table (1). Using tools with or without coating, 16 tests were carried out. Figure (1) shows used experimental set up [4]. rate.

TABLE I .SAMPLES SPECIFICATIONS IN ORTHOGONAL CUTTING IN THE LABORATORIES [4].

\begin{tabular}{|c|c|c|c|c|c|c|c|}
\hline $\begin{array}{c}\text { Test } \\
\text { No. }\end{array}$ & $\begin{array}{c}\text { Cutting }\{\mathbf{m} / \mathbf{m i n}\} \\
\text { Speed }\end{array}$ & Feed $\{\boldsymbol{\mu m} / \mathbf{r e v}\}$ & $\begin{array}{c}\text { Rake } \\
\text { angel }\end{array}$ & $\begin{array}{c}\text { Test } \\
\text { No. }\end{array}$ & $\begin{array}{c}\text { Cutting }\{\mathbf{m} / \mathbf{m i n}\} \\
\text { Speed }\end{array}$ & Feed $\{\boldsymbol{\mu m} / \mathbf{r e v}\}$ & $\begin{array}{c}\text { Rake } \\
\text { angel }\end{array}$ \\
\hline 1 & 200 & 150 & -7 & 5 & 300 & 150 & -7 \\
\hline 2 & 200 & 150 & 5 & 6 & 300 & 150 & 5 \\
\hline 3 & 200 & 300 & -7 & 7 & 300 & 300 & -7 \\
\hline 4 & 200 & 300 & 5 & 8 & 300 & 300 & 5 \\
\hline
\end{tabular}




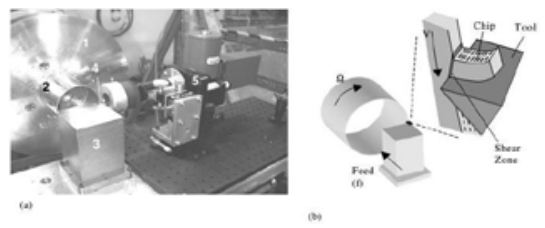

FIGURE I. .(A) PHOTOGRAPH OF THE EXPERIMENTAL SYSTEM SHOWING: 1- AIR BEARING SPINDLE; 2- AISI 1045 STEEL TUBE; 3MONOLITHIC TOOL POST; 4- ZERO RAKE ANGLE TUNGSTEN CARBIDE INSERT; 5- MICRO-PYROMETER SYSTEM, (B) SCHEMATIC DIAGRAM OF ORTHOGONAL CUTTING, A CUTTING CONFIGURATION THAT GENERATES A NEARLY TWO-DIMENSION AL PLASTIC FLOW OF MATERIAL [4]

\section{Evaluation of ANAlytical Models}

In this section an attempt is made to predict cutting forces, chip thickness, and shear plane angle implementing described models in section 2 for the cutting conditions and tool geometries summarized in Table 1 . The general equations used in analytical approaches are presented in Equations 4 to 8.

$$
\begin{aligned}
\mathcal{F} c= & \tau s . \mathcal{A} c / \sin \varphi[\cos \varphi-\sin \varphi \cdot \tan (\beta-\gamma)] \\
& r c=\frac{a c}{a o}=\sin \varphi / \cos ((\varphi-\gamma) \\
& \mathrm{Ft}=\mathrm{Fc} \cdot \tan (\beta-\gamma) \\
P s & =F c / A c \\
F c & =A \cdot K c
\end{aligned}
$$

Two rake angels of 5 and 7 degree with cutting speeds of 200 and $300 \mathrm{~m} / \mathrm{min}$, a depth of cut of $1.6 \mathrm{~mm}$, and $\tau s=$ $485 \mathrm{Mpa}$ are used to calculate desired parameters. Tables 3 to 6 and Figures 2 to 5 summarize the results.

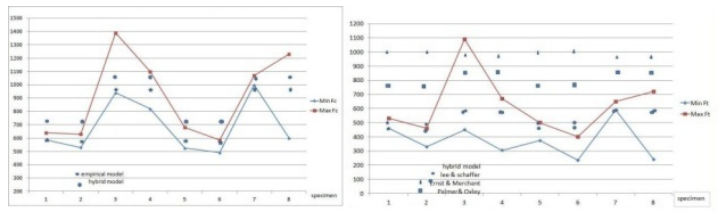

\section{FIGURE II. COMPARING THE PREDICTED HORIZONTAL FORCE WITH TEST DATA .}

\section{FIGURE III. COMPARISON OF CUTTING VERTICAL FORCES PREDICTED BY TEST RESULTS.}

\section{It is Shown in Figure 2 that:}

1) Fc values calculated using empirical model based on standard tables are in the range of minimum and maximum values obtained from the experiments. Therefore, it is demonstrated that reference formulas [2] can be applied with appropriate accuracy.

2) Fc values calculated using hybrid model for larger depths of cut are closer to reality $(0.3 \mathrm{~mm})$. This may be due to stronger effects of plowing action of tool nose in specific shear energy for lower depths of cut. It should be noted that the contribution of plowing force is neglected in descried analytical approach [3].

3) The cutting speed does not have an important influence on the accuracy of analytical models.

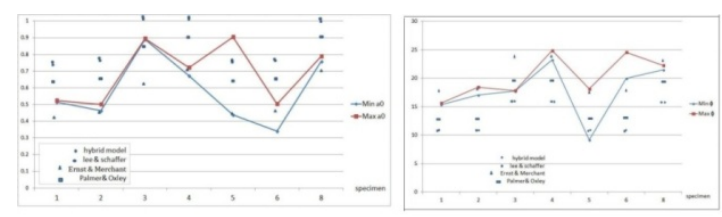

FIGURE IV. COMPARING OF PREDICTED CHIP THICKNESS WITH TEST RESULTS.

FIGURE V. COMPARING OF THE SHEAR PLANE ANGLE WITH TEST RESULTS.

According to what observed in Figures 3 to 5, comparing the thrust force Ft, chip thickness $\mathrm{a}_{\mathrm{c}}$ and shear plane angle $\varphi$ obtained from experiments with the predictions of hybrid, Lee-Schaffer, Merchant-Ernst, Palmer-Oxley models the following conclusion are made:

1) Ft values calculated using the hybrid models for test numbers 3, 4, 7, and 8 with higher values for depth of cut are closer to reality; while in the lower thickness, the values are out of range. Similar to what mentioned regarding Fc, this may be due to plowing effects of tool edge radius. Therefore hybrid model is not a proper model for cases with high values of specific cutting energy.

2) Examining two different levels of cutting speeds demonstrates that this parameter has no important effect on accuracy of predicted Ft.

3) The calculated Ft obtained from Lee-Schaffer theory is in good agreement with the result of hybrid model and experimental data.

4) Ft values calculated using Merchant-Ernst theory with the different values for depth of cut and cutting speed are out of the presented experimental range (reality). It seems that this model is not successful in prediction of Ft.

5) Ft values calculated using Palmer-Oxley theory show the same conditions as Merchant-Ernst theory and the same conclusion can be made for this one.

6) About chip thickness $\left(a_{0}\right)$, among the examined approaches the Merchant-Ernst model presents the best prediction, since the calculated values are closer to reality. The Palmer and Oxley theory is in the second place. However Lee and Schaffer is not proper model to calculate $a_{0}$.

7) About shear plane angle $(\varphi)$, among graphs and theories the Merchant-Ernst models presents the best answer, since the calculated values are closer to reality.

\section{CONCLUSION}

The assessment of proper machining models has been a goal for many researches done in the machining field. However complexity of this process makes it difficult to access. For example different chip type observed in different cutting conditions is a reason for the major change in chip removal mechanism. Therefore a unique model cannot simulate different governing mechanisms of chip formation for all cutting conditions. However suitable predictions can be expected from the available analytical models. The result of this study demonstrates that a unique model cannot predict all machining parameters successfully. In a more specific discussion, Merchant and Ernest model is successful in prediction of chip thickness and shear plane angle. However empirical and Lee-Schaffer models are appropriate models for 
prediction of horizontal cutting force and vertical thrust force, respectively. It must be noted that all mentioned analytical models (except empirical model) do not consider the plowing effect. Therefore the real phenomenon in the tool nose area is not captured properly. However this study shows the acceptable performance of analytical models, if the accuracy is not a main concern.

\section{REFERENCES}

[1] Merchant, E., 1998, Proceedings of the CIRP International Workshop on Modeling of Machining Operations, Atlanta, GA, USA.

[2] Reutlingen,Ulrich Fisher, Tabellenbuch Metall, 1992.

[3] Geoffrey Boothroyd, Winston A.Knight Marcel Dekker, Fundamentals of Machining and Machine Tools Second Edition, 1989.

[4] Assessment of Machining Models, Progress report R.W.Ivester, M.Kennedy, M.Davies, R.Stevenson, S.Thiele, R.Furness, S.Athavale. Machining Science and Technology, Vol.4, Issue 3, pp.511-538,2000.

[5] Amarego, E.J.A., Uthaichaya, M., Journal of Engineering Production 1(1):1-18.

[6] Shaw, M. C., 1984, Metal Cutting Principals, Oxford Press, Oxford, UK.

[7] Trent, 1991, Metal Cutting, Butterworth-Heinemann, Oxford.

[8] Komanduri, R., 1993, Appl Mech Rev, 46(3), 80-129.

[9] Mallock, A., 1881, Proc. Royal Soc (Lon), 33:127- 139.

[10] Piispanen, V., 1937, Teknillan Aiakakauslenti 27:315.

[11] Ernst, H., 1938, Physics of Metal Cutting, Machining of Metals, ASM, 1-34.

[12] Ernst, H., Merchant, M. E., 1941, Trans. ASME 29:299.

[13] Merchant, M. E., 1945, Trans. ASME, 66:A65-A71.

[14] Merchant, M. E., 1945, J. App. Phys.,16:267.

[15] Merchant, M. E., 1945, J. App. Phys., 16:318.

[16] Ernst, H., Merchant, M.E., 1941, Chip formation, friction and high quality machined surfaces, urface Treatment of Metals, Vol. 29, p. 299.

[17] Merchant, M.E., 1945, Mechanics of the cutting process, Journal of Applied Physics, Vol. 16, p. 67318.
[18] Lee, E.H., Schaffer, B.W., 1951, The theory of plasticity applied to a problem of machining, Journal of Applied Mechanics, Vol. 18(4), p. 405.

[19] Palmer, W.B., Oxley, P.L.B., 1959, Mechanics of metal cutting, Proceedings of Institute of Mechanical Engineers, Vol. 173, p. 623.

[20] Oxley, P.L.B., 1961, A strain hardening solution for the shear angle in orthogonal metal cutting, International Journal of Mechanical Sciences, Vol. 3, p. 68.

[21] Johnson, W., 1962, Some slip-line fields for swaging or expanding, indenting, extruding and machining with curved dies, International Journal of Mechanical Sciences, Vol. 4, p. 323.

[22] Oxley, P.L.B., Hatton, A.P., 1963, Shear angle solution based on experimental shear zone and toolchip interface stress distribution,International Journal of Mechanical Sciences, Vol. 5, p. 41.

[23] Oxley, P.L.B., Welsh, M.J.M., 1963, Calculating the shear angle in orthogonal metal cutting from fundamental stress, strain, strain-rate properties of the work material, Proceedings 4th International Machine Tool Design and Research Conference. Pergamon, Oxford, p. 73.

[24] Usui, E., Hoshi, K., 1963, Slip-line fields in metal cutting involving centered fan fields, International Research in Production Engineering ASME, p. 61.

[25] Kudo, H., 1965, Some new slip-line solutions for twodimensional steady-state machining, International Journal of Mechanical Sciences, Vol. 7, p. 43.

[26] Fenton, R.G., Oxley, P.L.B., 1968, Mechanics of orthogonal machining : allowing for the effects of strain-rate and temperature on tool-chip friction, Proceedings of Institute of Mechanical Engineering.

[27] Dewhurst, P., Collins, I.F., 1973, A matrix technique for constructing slip-line field solutions to a class of plane-strain plasticity problems, International Journal of Numerical Methods in Engineering, Vol. 7, p. 357.

[28] Chandrasekharan, V., Kapoor, S.G., DeVor, R.E., 1993, A mechanistic approach to predicting the cutting forces in drilling : with application to fiberreinforced composite materials, ASME, MD-Vol. 45/PED-Vol. 66, Proc. Machining of Advanced Composites, pp. 33 - 51.

[29] Endres, W.J., DeVor, R.E., Kapoor, S.G., 1993, A dual-mechanism approach to the prediction of machining forces, Parts 1 and 2, Proc., ASME Sym. on Modeling, Monitoring and Control Issues in Manufac., PED-Vol. 64, pp. 563-593. 